Printed in Sweden

\section{Spread chromosomal nucleoli of Chironomus salivary glands}

J. DERKSEN, M. F. TRENDELENBURG, U. SCHEER and W. W. FRANKE, Department of Genetics, Faculty of Sciences, University of Nijmegen, The Netherlands, and Department of Cell Biology, Institute of Biology II, University of Freiburg i.Br., Germany, BRD

In eukaryotic cells the transcription of ribosomal DNA (rDNA), i.e. of the cistrons of pre-ribosomal RNA (pre-rRNA), has been directly visualized in the extrachromosomal (amplified) nucleoli of amphibian oocytes by electron microscopic techniques. The transcribing rDNA appears in spread preparations as deoxyribonucleoprotein (DNP) axes which are associated, in regular periods, with cascades of lateral, growing rRNP fibrils separated by free ('spacer') sections [4-6, 13]. The morphological data obtained are in agreement with the corresponding biochemical and physicochemical determinations. Ribosomal RNA cistrons integrated into chromosomes have not yet been clearly identified. Although recently micrographs of spread preparations from total $\mathrm{HeLa}$ cell lysates have been presented from Miller's laboratory which show similar, though not highly repeated, matrix units of laterally attached RNP fibrils on DNP axes [3]; this cannot be considered as a clear demonstration of intrachromosomal rRNA cistrons in transcription.

We have chosen for our preparations nuclei of Chironomus salivary glands because (i) of the chromosomal polyteny, (ii) the large size of the nuclei and nucleoli which make them suitable for preparative manipulations, and (iii) the good background of knowledge concerning the nucleolar cytology and biochemistry of these cells (see, e.g., $[9,10]$ ).

\section{Materials and Methods}

Salivary glands of Chironomus thummi were prepared and transferred into a medium modified from Robert [11] containing $0.087 \mathrm{~N} \mathrm{NaCl}, 0.032 \mathrm{~N} \mathrm{KCl}, 0.01 \mathrm{M}$ EDTA and $0.01 \mathrm{M}$ Tris-maleate, $\mathrm{pH}$ 6.3. The dissected glands were disrupted by syringing and the liberated, crude nuclei were transferred into a drop of bidistilled water, adjusted to $\mathrm{pH} 9.0$ with $0.01 \mathrm{M}$ borate buffer and allowed to swell for $15 \mathrm{~min}$. After swelling the cytoplasmic remnants were removed from the nuclei by syringing and the nuclei were transferred into a fresh drop of ' $\mathrm{pH}$ 9-water'. The nuclei were disrupted by hand using watchmakers forceps, and were processed essentially according to the method described by Miller \& Beatty [4] and Miller \& Bakken [3] as modified by Scheer et al. [13]. Electron micrographs were made either in a Zeiss EM9 or a Siemens 101, and the magnification indicators were controlled using grating replicas. 


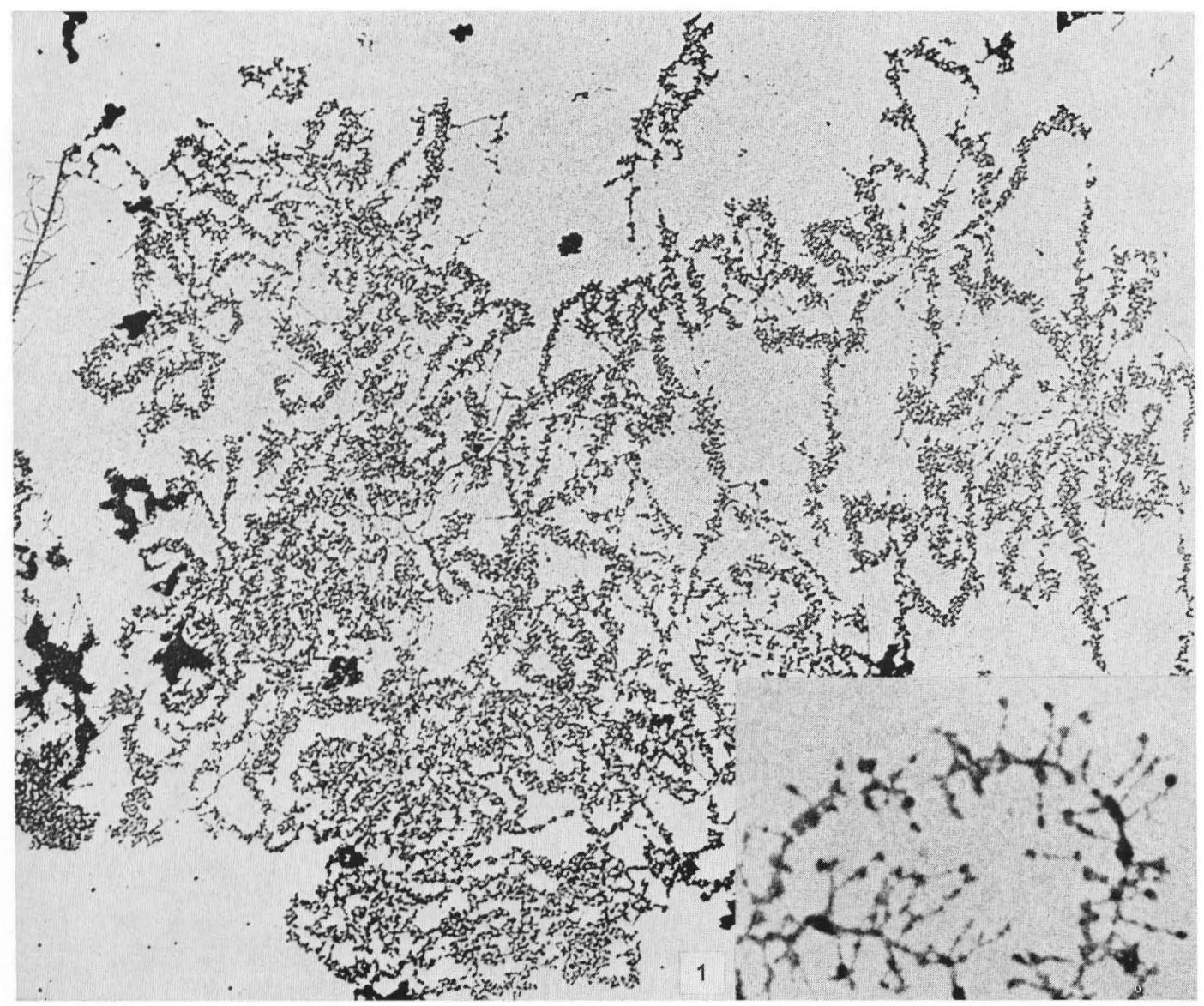

Fig. 1. Survey electron micrograph of putative transcribing rDNAlin spread preparations of nuclei manually isolated from Chironomus thummi salivary glands. The inset shows, at higher magnification, the lateral fibrils inserting at the DNP-axis with their terminal dense nodules. $\times 11700$; inset $\times 56000$.

\section{Results and Discussion}

Good nucleolar spreads are much harder to obtain from the salivary gland nuclear contents than with the amphibian oocytes (especially from urodela). This may be largely due to the greater amount of non-nucleolar material present. Fig. 1 shows a survey micrograph of what we interpret as a nucleolar spread. One recognizes DNP axes (magnified in fig. 2) which are for the most part associated with lateral fibrils. These fibrils exhibit at many sites the typical length gradients and reveal the separation of matrix units and 'free' segments, i.e. stretches not covered with fibrils. The matrix units (some startpoints are indicated in fig. 2 by arrows, termini are denoted by bars) were of an average length of $2.2 \mu \mathrm{m}$ with a relatively wide range (1.9 to $2.6 \mu \mathrm{m}$ ). The free ('spacer') segments (for the divergent terminology of 'spacer' see $[4,8,13$, 14]) appear to be very short (mean: $0.45 \mu \mathrm{m}$; range 0.15 to $0.68 \mu \mathrm{m}$ ). Some situations (e.g. fig. 2) suggest that lateral fibrils can also occur within the 'spacer' regions, similar to what has been observed in the extrachromosomal oocyte nucleoli of various amphibia [13]. The lateral fibrils are, when strongly expanded, approx. $150 \AA$ thick and, like 


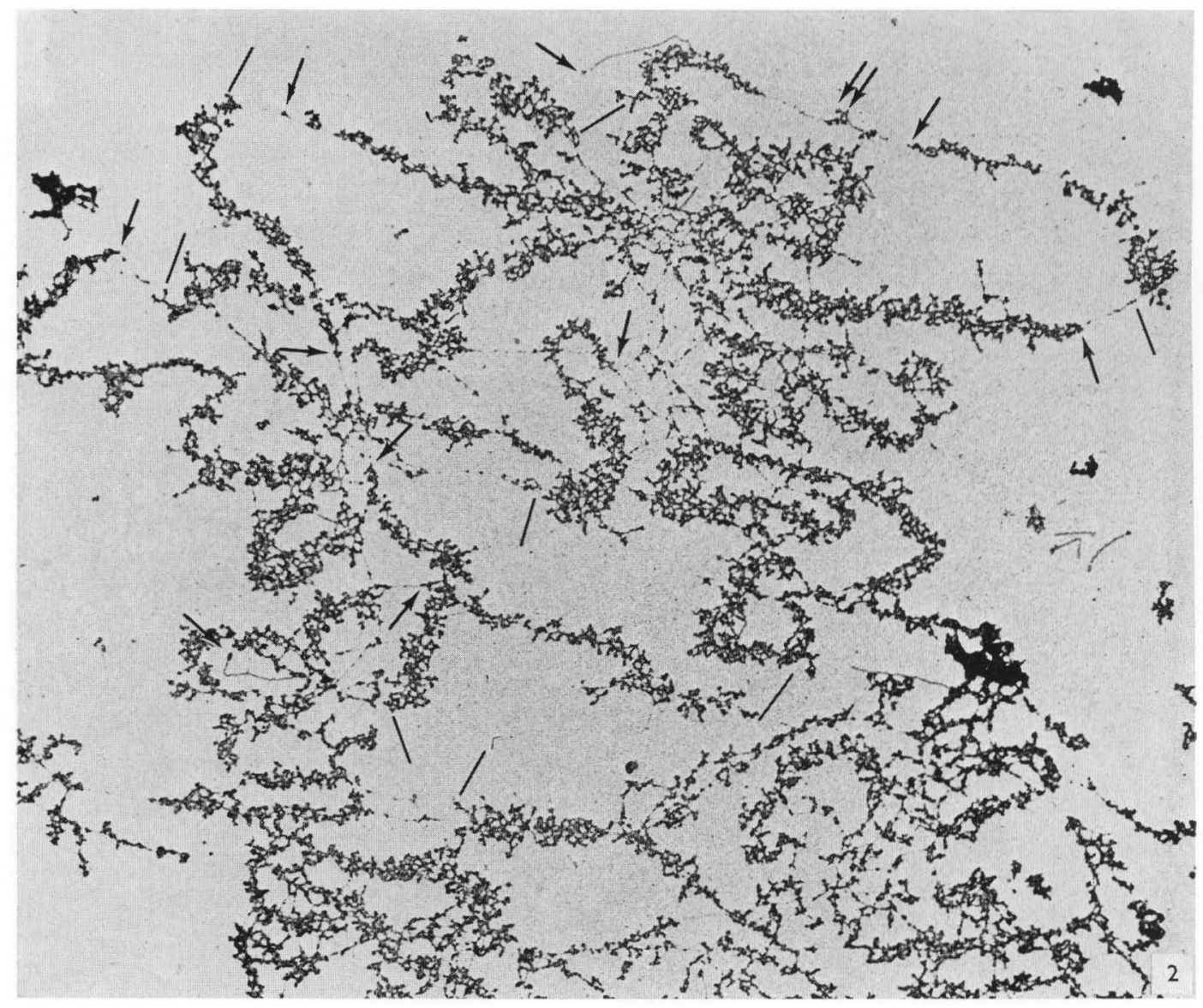

Fig. 2. Partial magnification from fig. 1 demonstrating matrix units separated by free axial segments. The short arrows indicate startpoints of matrix units, the bars denote termini. The two long arrows point to long, stretched lateral RNP-fibrils. The double arrow points to a situation which might represent formation of rRNP fibrils within a 'spacer' region. $\times 19000$.

those described for the amphibian extrachromosomal nucleoli by Miller \& Beatty [5] frequently show terminal knobs. The maximal length of such fibrils (in particular those inserting in the terminal parts of matrix units) was measured as $1 \mu \mathrm{m}$.

The identification of the lateral and axial structures as RNP and DNP, respectively, is still presumptive and based on morphological homology only: The structures observed have essentially the same characteristics as the spread transcription units of rDNA in the extrachromosomal amphibian oocyte nucleoli.
They show only two components, namely the axial and the lateral fibrils, a repeat pattern of matrixcovered and non-covered regions, and a length gradient of the lateral fibrils within one matrix unit. The lengths of the matrix units, taken as double-stranded B-form DNA, could code for 1.8 to 2.5 million D RNA, i.e. values which approach the mol wts determined for the pre-rRNA of Chironomus tentans $\left(2.6 \times 10^{6} \mathrm{D},[12] ; 3.3 \times 10^{6} \mathrm{D},[9]\right)$ and other diptera [2, 7]. From the structural homology and from the agreement of the morphological and biochemical data we con- 
clude that our micrographs present the transcribing rDNA of the nucleoli contained in the polytene chromosomes of the Chironomus salivary glands. We have to emphasize, however, that the relative length of free ('spacer') axis is much below the corresponding values found in amphibian oocytes [4, 5, 13] and in the HeLa cells [1, 3].

We thank Dr H. D. Berendes, University of Nijmegen, and $\mathrm{Dr}$ H. Falk, University of Freiburg, for various support and Miss Marianne Winter for skilful technical assistance.

The study received financial support from the EMBO (short-term fellowship awarded to J. D.) and the Deutsche Forschungsgemeinschaft, SFB 46 (grant awarded to W. W. F.).

\section{References}

1. Bakken, A H \& Miller, O L, J cell biol 55 (1972) 12a.

2. Dalgarno, L, Hosking, D M \& Shen, C H, Eur $\mathbf{j}$ biochem 24 (1972) 498.

3. Miller, O L \& Bakken, A H, Acta endocrinol, suppl. 168 (1972) 155.

4. Miller, O L \& Beatty, B R, Science 164 (1969) 955.

5. - Genetics, suppl. 61 (1969) 134.

6. Miller, O L \& Hamkalo B A, Int rev cytol 33 (1972) 1.

7. Perry, R P, Cheng, T-Y, Freed, J J, Greenberg, J R, Kelley, D E \& Tartof, K D, Proc natl acad sci US 65 (1970) 609.

8. Reeder, R H \& Brown, D D, J mol biol 51 (1970) 361.

9. Ringborg, U, Daneholt, B, Edström, J-E, Egyházi, E \& Lambert, B, J mol biol 51 (1970) 327.

10. Ringborg, U \& Rydlander, L, J cell biol 51 (1971) 355 .

11. Robert, M, Chromosoma 36 (1971) 1.

12. Rubinstein, L \& Clever, U, Biochim biophys acta 246 (1971) 517.

13. Scheer, U, Trendelenburg, M F \& Franke, W W, Exptl cell res 80 (1973) 175.

14. Wensink, P C \& Brown, D D, J mol biol 60 (1971) 235.

Received March 5, 1973

Revised version received May 14, 1973 